\title{
Hip Joint: Embryology, Anatomy and Biomechanics
}

\author{
Ahmed Zaghloul $^{1 *}$ and Elalfy M Mohamed ${ }^{2}$ \\ ${ }^{1}$ Assistant Lecturer, Department of Orthopedic Surgery and Traumatology, Faculty of Medicine, Mansoura University, Egypt \\ ${ }^{2}$ Domenstrator, Department of Orthopedic Surgery and Traumatology, Faculty of Medicine, Mansoura University, Egypt
}

Received: 制: December 11, 2018; Published: 制: December 20, 2018

*Corresponding author: Ahmed Zaghloul, Assistant Lecturer, Department of Orthopedic Surgery and Traumatology, Faculty of Medicine, Mansoura University, Egypt

\begin{abstract}
Introduction: Hip joint is matchless developmentally, anatomically and physiologically. It avails both mobility and stability. As the structural linkage between the axial skeleton and lower limbs, it plays a pivotal role in transmitting forces from the ground up and carrying forces from the trunk, head, neck and upper limbs down. This Article reviews the embryology, anatomy and biomechanics of the hip to give a hand in diagnosis, evaluation and treatment of hip disorders.

Discussion: Exact knowledge about development, anatomy and biomechanics of hip joint has been a topic of interest and debate in literature dating back to at least middle of $18^{\text {th }}$ century, as Hip joint is liable for several number of pediatric and adult disorders. The proper acting of the hip counts on the normal development and congruence of the articular surfaces of the femoral head (ball) and the acetabulum (socket). It withstands enormous loads from muscular, gravitational and joint reaction forces inherent in weight bearing.

Conclusion: The clinician must be familiar with the normal embryological, anatomical and biomechanical features of the hip joint. For early diagnosis, evaluation and proper treatment of hip disorders.
\end{abstract}

\section{Embryology}

\section{Embryology and Development of the Hip Joint}

Three weeks after fertilization, primitive limb buds are already beginning to form in the embryo. Strayer demonstrated that these are initially filled with mesenchyme which differentiates in time to form all joint components except for the blood vessels and nerves [1].

The 6-week embryo is 12 -mm long. Areas within the mesenchyme have condensed to outline the ilium, ischium, pubis, and femoral shaft. Rapid differentiation follows. The femoral head appears slightly later than the femoral shaft but by 7 weeks, when the embryo is $17-\mathrm{mm}$ long, an inter-zone develops between the femoral head and the acetabulum. Three separate layers develop within this inter-zone and come to form the perichondrium of the acetabulum and the femoral head together with the synovial membrane [1].

By 8 weeks the embryo is $30-\mathrm{mm}$ long and blood vessels have grown into the ligamentum teres. There is the beginning of angulation of the femoral neck upon the femoral shaft. The cleft which heralds the true joint cavity begins to develop by apoptosis and the acetabular labrum is identifiable as a separate entity [1]. At 11 weeks the embryo is $50-\mathrm{mm}$ long. The femoral head is spherical and $2 \mathrm{~mm}$ in diameter. It is clearly separate from the acetabulum and Watanabe (1974) showed that it was possible experimentally to dislocate the hip for the first time at this age. The NSA now measures $140-150^{\circ}$; it is already possible to detect femoral anteversion between 5 and $10^{\circ}$; the vascular supply to the hip is established.

The 16-week fetus is 120 -mm long. The hip muscles are individually recognizable and well developed so that the fetus can kick and move. The femoral shaft shows early ossification within its cartilage anlage but the femoral head and trochanters remain cartilaginous until well after birth. In utero fetal hips lie typically in flexion, abduction and external rotation, with the left hip usually being the more rotated. The blood supply to the femoral head is predominantly through the epiphyseal and metaphyseal vessels. The vessels in the ligamentum teres are insignificant at this stage but contribute more to the femoral head blood supply later in gestation. During the last 20 weeks of intra-uterine life the hip joint enlarges and matures [1]. 


\section{Hip Growth After Birth}

Acetabular growth is complex: the triradiate cartilage contributes $70 \%$, enlarging both in diameter and depth. At the interface between the pelvic bones and the triradiate cartilage double growth plates allow the circumferential enlargement of the cavity to accommodate the growing femoral head. Growth plates extend also beneath the articular surface of each pelvic bone [2].

The acetabular ring epiphysis which surrounds the acetabular margin contributes nearly $30 \%$ to acetabular depth. Small centers of ossification appear in the ring epiphysis between 11 and 14 years. It usually fuses to the acetabular margin in mid-adolescence. The triradiate cartilage closes at about 11 years in girls and a year later in boys [2]. Development of the proximal femoral chondroosseous epiphysis and physis is probably the most complex of all the appendicular skeletal growth regions [3]. Figure 1 illustrates several stages in the development of the proximal femur. Perhaps the two most important features are (1) the continuity of epiphyseal and physeal cartilage along the posterosuperior neck throughout much of postnatal development and (2) the intracapsular course of the limited capital femoral blood vessels.
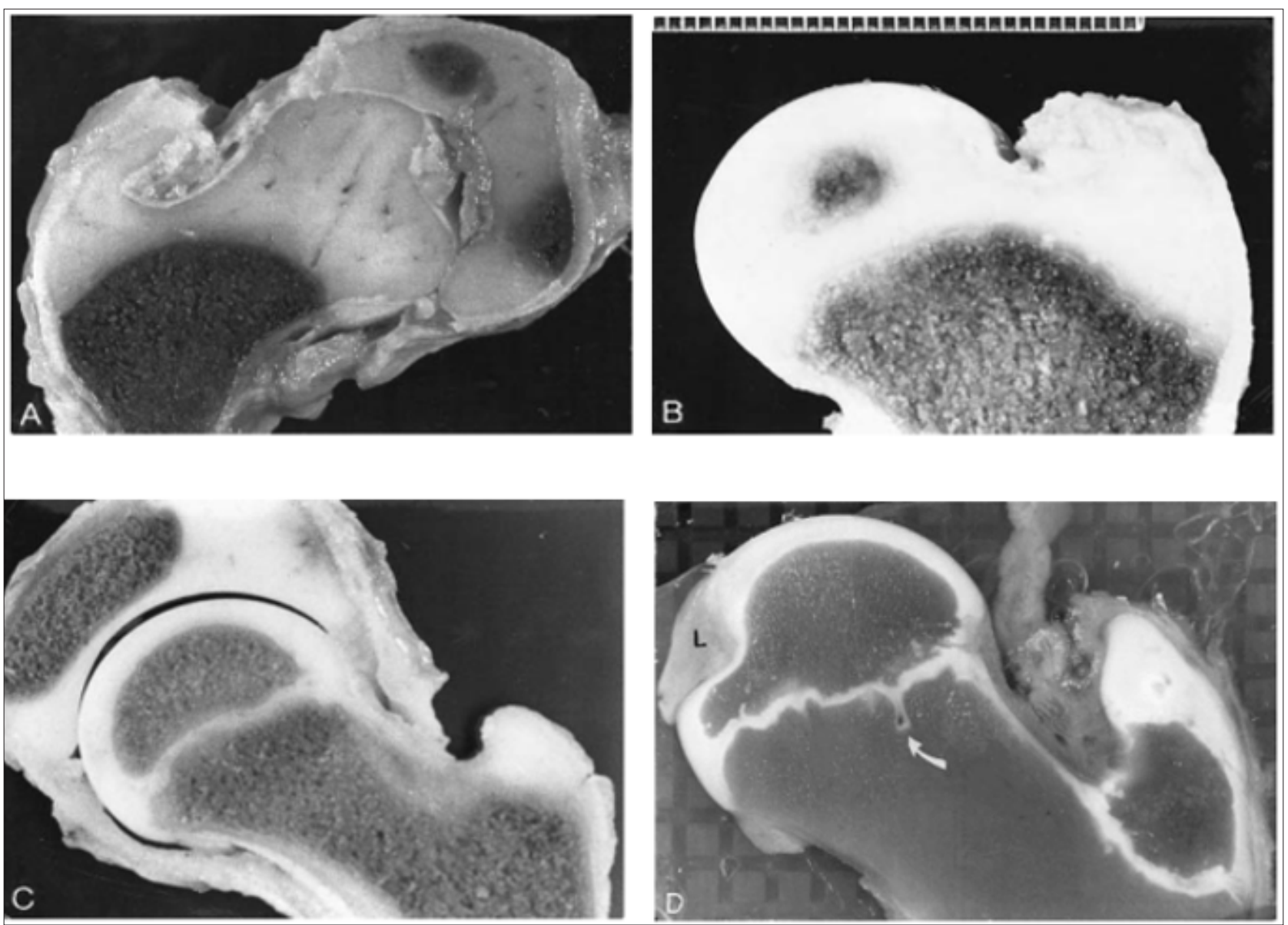

Figure 1: Slab sections showing proximal femoral development. (A) At 2 months a contiguous epiphysis encompasses the capital femur and greater trochanter. The intrinsic vascularity of the capital femoral cartilage is evident. (B) At 8 months the capital femoral ossification center is developing, and the femoral neck (metaphysis) is forming. (C) At 8 years undulations are developing in the capital femoral physis. (D) At 12 years there is a normal indentation of the ossification center at the site of attachment of the capital femoral ligament (L); the capital femoral physis is extensively undulated, and a mammillary process (arrow) is evident (Ogden JA, 1983).

Secondary ossification usually begins in the capital femur by 4-6 months postnatally (range 2-10 months). This process is a centrally located sphere of ossification that expands centrifugally, eventually conforming to the hemispheric shape of the articular surface by the time the child is 6-8 years old and forming a discrete subchondral plate that follows the capital femoral physeal contour [3]. Throughout most of the development the capital femoral and trochanteric epiphyses have a cartilaginous continuity along the posterior and superior portions of the femoral neck (Figure 2 ). Although this region gradually thins as the child grows, it is essential for the normal latitudinal growth of the femoral neck and, in part, the normal decrease in anteversion (Figure 2).

Selective growth along the capital femorointertrochanteric physis establishes a discrete femoral neck. The primary spongiosa initially formed during neck development is not completely oriented to biologic forces across the hip joint. The more responsive secondary spongiosa begins to form the typical trabecular patterns oriented to compression and tension forces. This process becomes more prominent during the second decade of life. The area between these major osseous patterns is often referred to as Ward's triangle. 


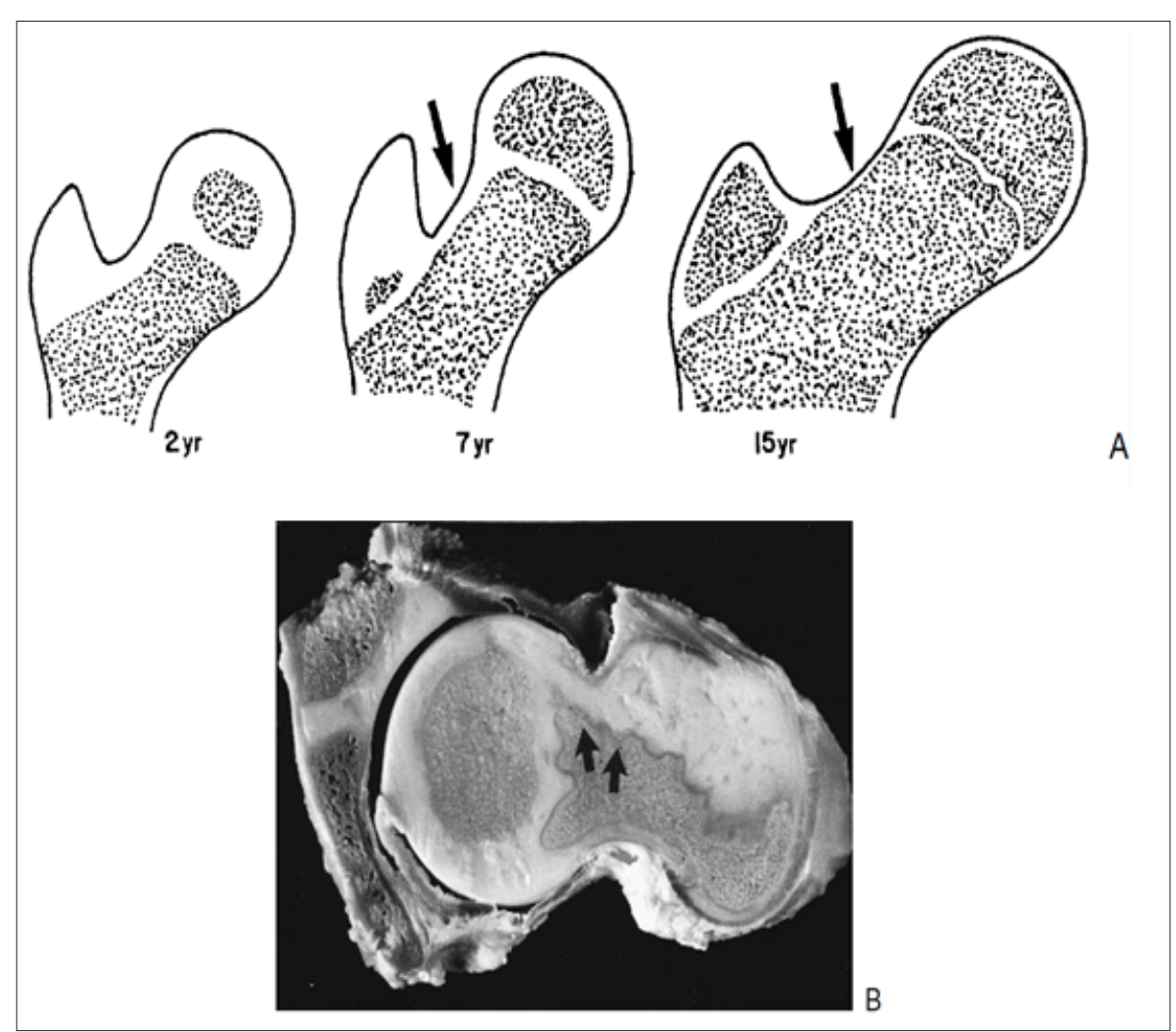

Figure 2: (A) Progressive proximal femoral development. A segment of physeal cartilage (arrows) is present along the posterosuperior femoral neck throughout most of development. It is necessary for widening of the femoral neck and posteriorly directed growth of the femoral neck to spontaneously decrease the amount of anteversion. (B) Transverse section through the proximal femur showing the capital femoral epiphysis and the posterior cartilaginous continuity (arrows) with the unossified greater trochanter (Ogden JA, 1983).

The development of the femoral neck brings about changes in the contour of the capital femoral physis. Initially, the femoral neck is transversely directed (Figure 1); but during the first year there is preferential growth in the medial, and middle sections. As these regions develop, the capital femoral physis becomes more medially (Varus) and posteriorly oriented, which eventually may predispose to slipped capital femoral epiphysis. Lappet formation, undulations, and mammillary processes develop in the physis (Figure 1), again becoming more evident after 10 years of age. These processes and contours serve to "anchor," or stabilize, the capital femoral epiphysis to prevent displacement due to biologic shear stresses [3].

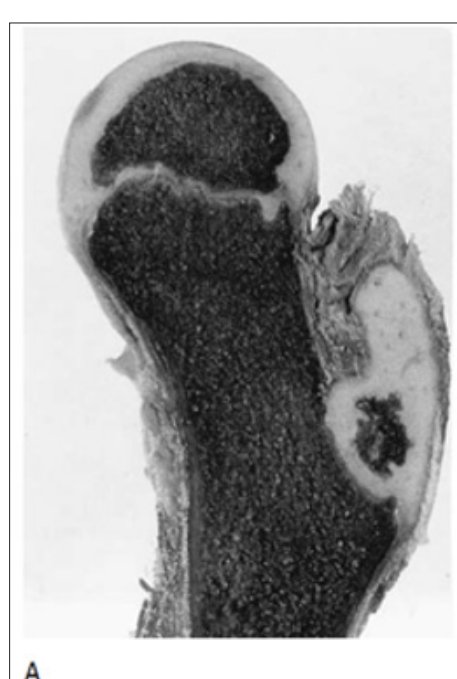

A

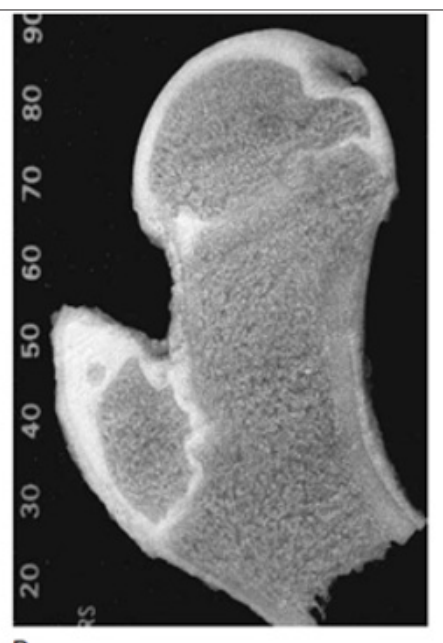

B

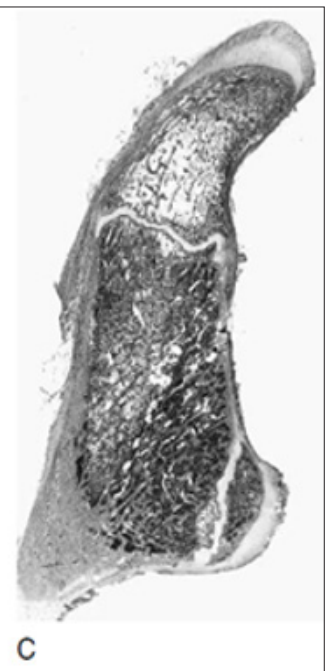

C

Figure 3: (A) Development of trochanteric ossification in an 8-year-old child, showing the irregular margins of secondary ossification and the extensive cartilaginous nature of the trochanteric epiphysis, especially proximally at the tip. (B) Later stage (12years) showing an accessory (tertiary) ossification center. (C)Histologic section through the greater and lesser trochanters in a 15-year-old boy (Ogden JA, 1983). 
Ossification begins in the greater trochanter at 5-7 years (Figure 3 ) and is initially present directly above the trochanteric physis. With further development, ossification proceeds cephalad into the remainder of the epiphysis. Epiphysiodesis of the greater trochanter occurs at 14-16 years (usually later than in the capital femoral physis). The lesser trochanter does not usually ossify until adolescence (Figure 3). Fusion occurs between 15 and 19 years. This region is subject to high tensile stresses from the attached iliopsoas tendon and represents a traction apophysis. Overgrowth may occur owing to chronic stress, as with cerebral palsy.

\section{Anatomy}

The hip is considered as a ball and socket joint. It meets the four principle features of a synovial or diarthrodial joint 1- a joint cavity 2- joint surfaces are covered with articular cartilage 3- a synovial membrane producing synovial fluid 4- a ligamentous capsule [4]. For ease of approach we have considered the relevant anatomy under the heading's Bony anatomy, Ligaments and capsular anatomy, Neurovascular anatomy and Muscular anatomy (Figure 4) [5].

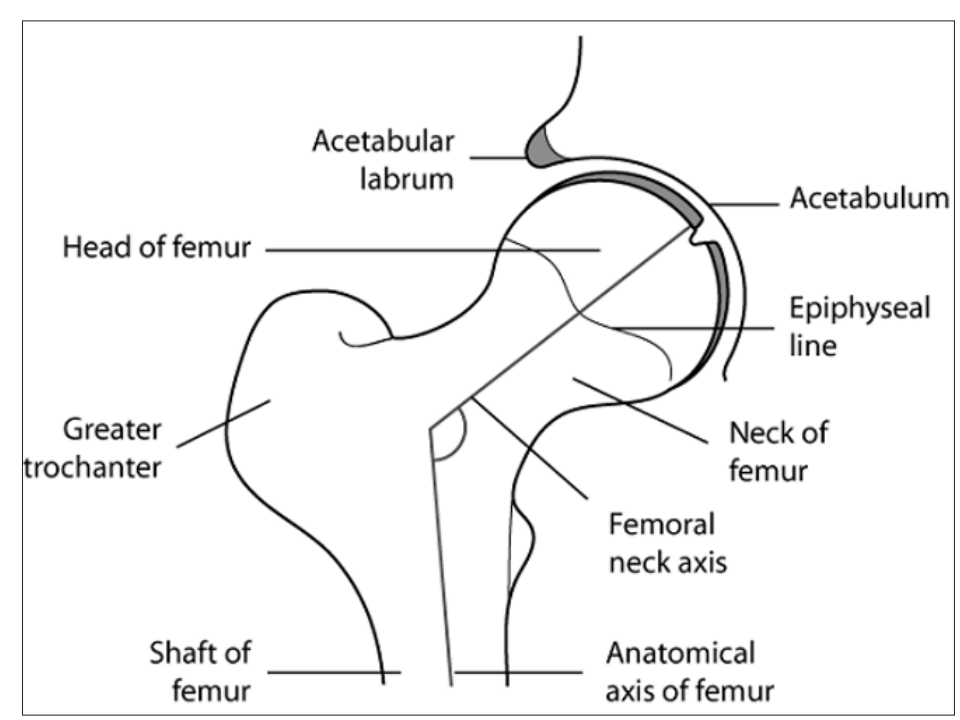

Figure 4: Cross-sectional view of the normal hip joint (Damien et al., 2010).

\section{Bony Anatomy}

The cup-shaped acetabulum is formed by the innominate bone with contributions from the ilium (approximately $40 \%$ of the acetabulum), ischium (40\%) and the pubis (20\%) [6]. In the skeletally immature these three bones are separated by the triradiate cartilage - fusion of this starts to occur around the age of $14-16$ years and is complete usually by the age of 23 [7].

The articular surface is lunate shaped from inside. Within the lunate there is a central inferior acetabular fossa. This fossa contains a synovial covered fat pad and the origin of the ligamentum teres. The inferior transverse completes the socket of the hip joint. A strong fibro-cartilaginous labrum is anchored to the rim of the acetabulum. It has an important function in the development and distribution of forces around the hip joint [8]. Another function is restricting movement of synovial fluid to the peripheral compartment of the hip, it leads to exert a negative pressure effect inside the hip joint [9]. The labrum runs around the circumference of the acetabulum, at its inferior part the transverse acetabular ligament crosses the acetabular fossa. It is attached to the bony rim of the acetabulum and is separate from the attachment of the capsule [10].

The femoral head is covered with an articular cartilage beyond the reaches of the acetabular bony rim to accommodate the full range of motion. The covered region represents from 60 to $70 \%$ of a sphere. There is an uncovered area on the central area of the femoral head that is called the fovea capitis, for the insertion of the ligamentum teres. The ligamentum teres does not contribute to the stability of the joint. It is covered in synovium, so despite it is intraarticular it is actually extra-synovial component [5].

The femoral head is attached to the femoral shaft by the neck, which varies in length according to the body size body size. The NSA is usually $125 \pm 5^{\circ}$ in the normal adult, with coxa valga being the condition when this value exceeds $130^{\circ}$ and coxa vara when the inclination is less than $120^{\circ}$ (Figure 5) [5]. This feature is important due to the femoral shaft is laterally displaced from the pelvis, this leads to facilitating freedom of joint motion. Any significant deviation in angle outside this typical range will increase or decrease the lever arms used to produce motion by the abductor muscles markedly. Remodeling of bone due to changing stress patterns leads to a decrease in the NSA from $150^{\circ}$ after birth to $125^{\circ}$ in the adult (Figure 6) [11].

There is a slight anterior rotation in relation to the coronal plane in the femoral neck. This is called a femoral anteversion (Figure 7) [11]. The angle of anteversion is measured as the angle between a mediolateral line through the knee and a line through the femoral head and shaft. The average range for femoral anteversion is from $15^{\circ}$ to $20^{\circ}$ [5]. At the junction of the femoral neck and shaft, the greater trochanter projects superolaterally and the lesser trochanter projects posteromedially. The orientation of these bony prominences significantly influences the function of the muscles that insert on them. 


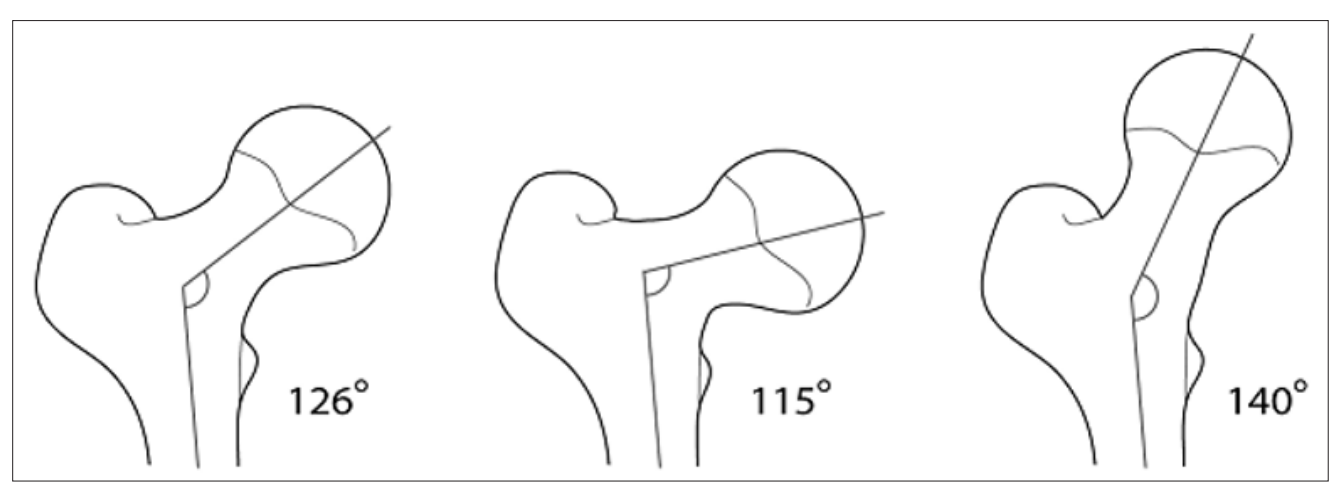

Figure 5: (a) Normal femoral NSA, (b) a decreased femoral NSA (coxa vara) and (c) an increased femoral NSA (coxa valga) (Damien et al., 2010).

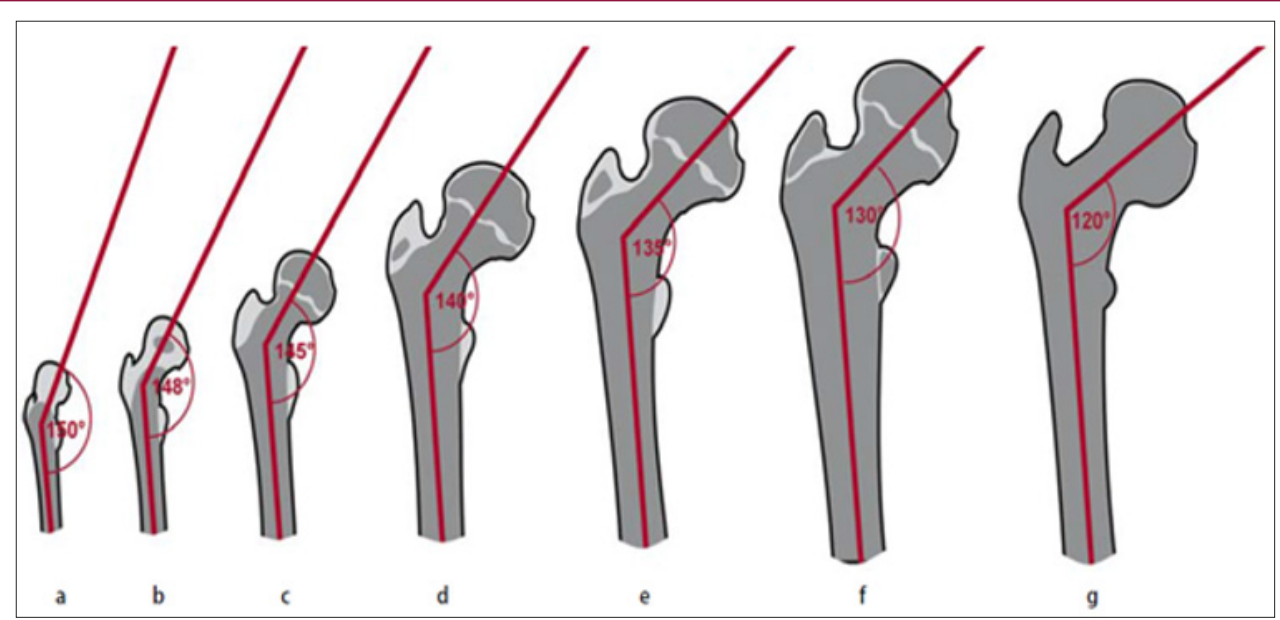

Figure 6: Development of the neck-shaft angle: a at birth, b at the age of 1 year, c 3 years, d 5 years, e 9 years, $f 15$ years, $g$ in adulthood (Hefti, 2007).

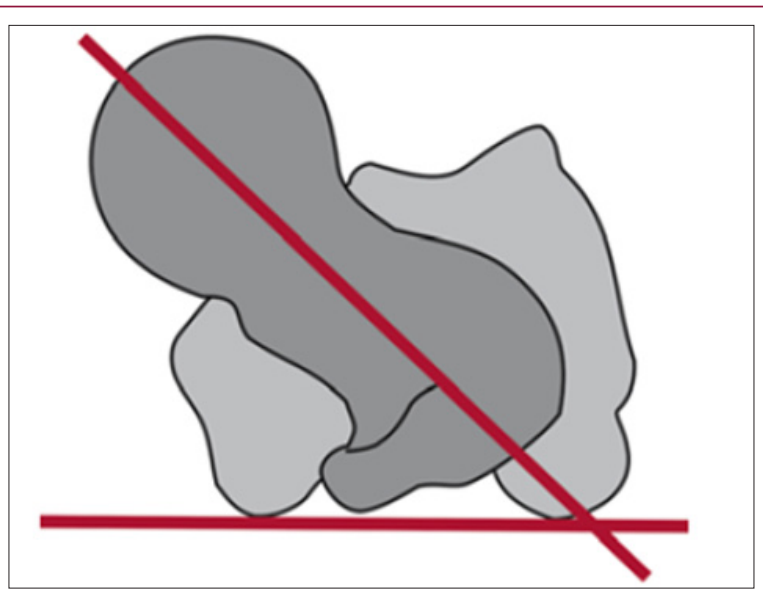

Figure 7: Presentation of the anatomical anteversion angle: Anteversion refers to the spatial angle formed between the horizontal plane and the plane of the femoral neck. The knee condyles and femoral neck are projected in an overlapping position (Hefti, 2007).

During weight bearing activities, the proximal femur is subjected to tremendous tensile and compressive stresses, especially at the intertrochanteric and subtrochanteric regions. Trabecular bone patterns develop to resist these deforming forces. Ward described these trabecular patterns and attributed their orientation to the directional alignment of weight bearing stress exerted on the proximal femur (Figure 8). These trabeculae consist of a primary compressive group, which arises from the medial subtrochanteric cortex and ascends superiorly into the weight bearing femoral head, and a primary tensile group, which spans from the foveal area of the femoral head, through the superior femoral neck, and into the lateral subtrochanteric cortex. Secondary compressive, secondary 
tensile and a greater trochanteric group complete the pattern of trabecular orientation [12]. The calcar femorale is a dense plate of bone extending laterally from the posteromedial femoral cortex to the posterior aspect of the greater trochanter. The calcar is thickest at its medial aspect and gradually thins as it extends laterally $[13,14]$.

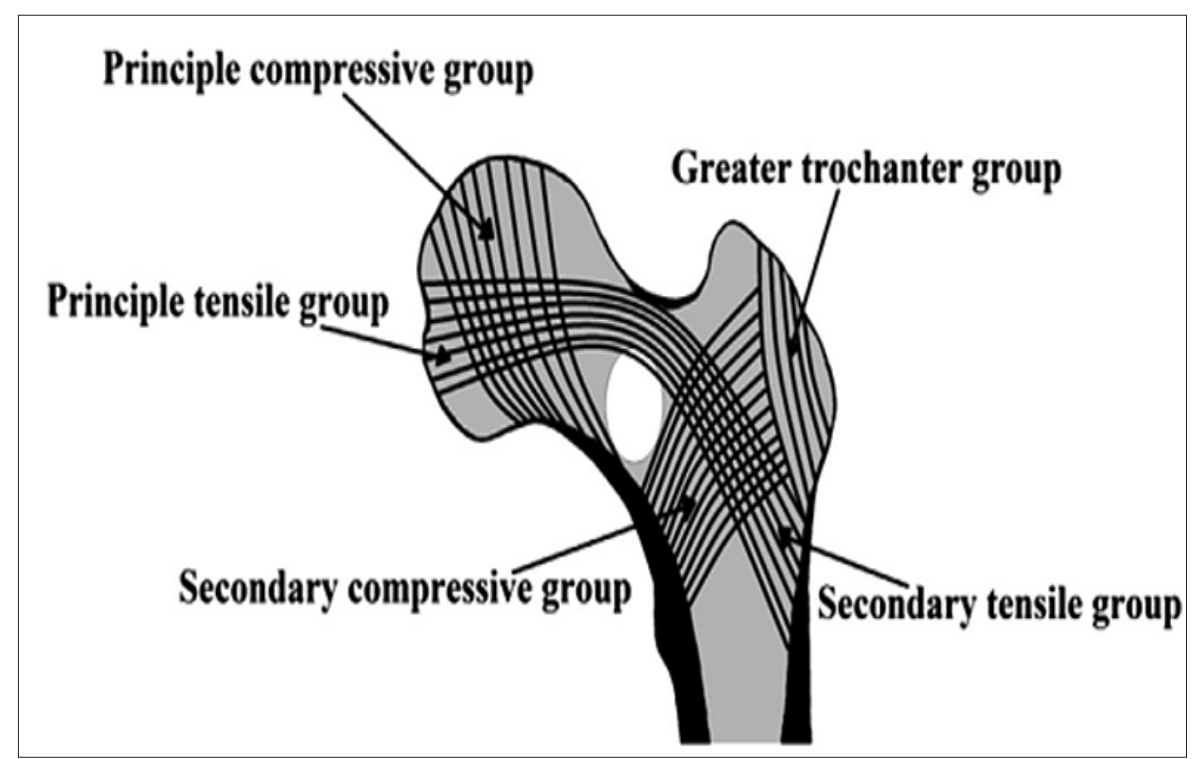

Figure 8: Diagrammatic representation of the five normal groups of trabeculae in the proximal femur. Ward's triangle (white color) corresponds to the anatomic region in the femoral neck where tensile and compressive forces balance each other (Ward, 1838).

\section{Ligaments and Capsular Anatomy}

A strong fibrous capsule encloses the hip joint that aids in the maintenance of hip stability. Proximally, the capsule attaches to the bony rim of the acetabulum approximately $6 \mathrm{~mm}$ to 8 $\mathrm{mm}$ from the labrum [10]. At its distal (femoral) insertion, the anterior capsule attaches to the intertrochanteric line and greater trochanter, whereas the posterior capsule attaches just proximal to the posterior intertrochanteric line [15]. Although most of the capsular fibers run longitudinally parallel to the femoral neck, a smaller subset of fibers, the zona orbicularis, encircles the femoral neck. This condensed group of circular fibers reinforces the hoop stresses encountered by the acetabular labrum [16].

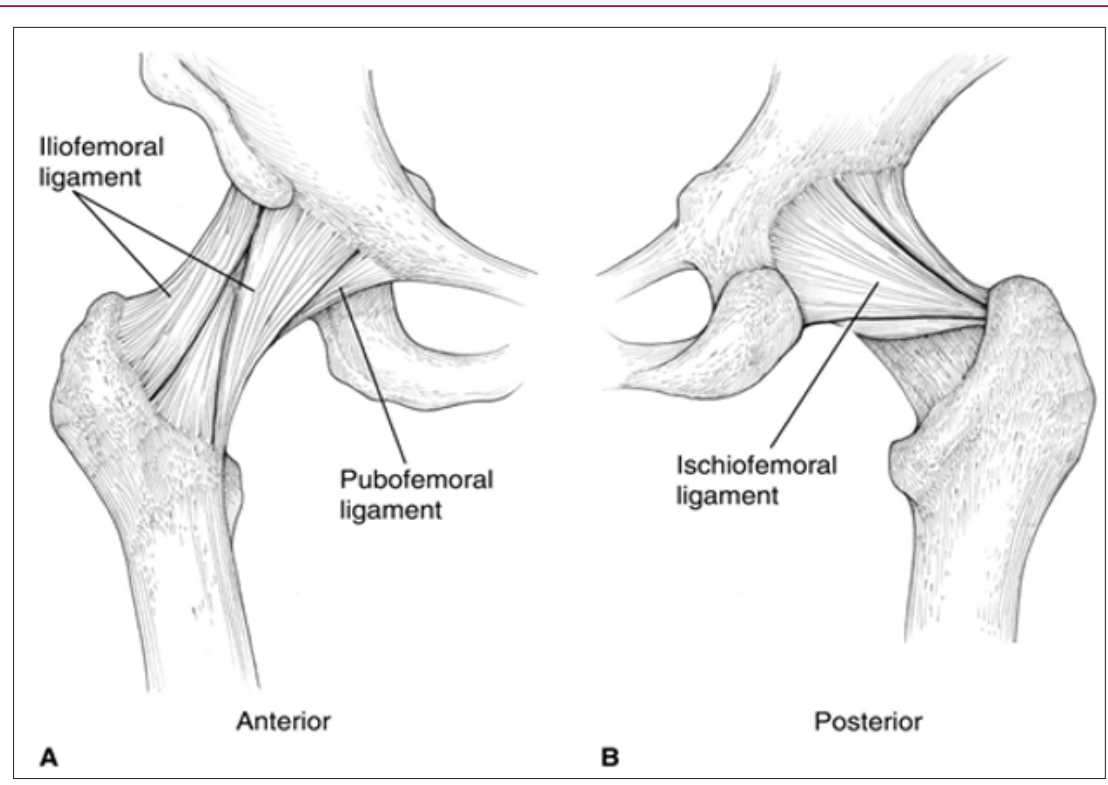

Figure 9: Extra-capsular ligaments reinforcing the hip capsule. A: Anterior view. B: Posterior view (Sim et al., 1995).

The inner surface of the capsule is lined by the synovium of the hip joint. The synovial lining also covers the acetabular fossa, labrum, and intracapsular portion of the femoral neck [15]. Three extracapsular ligaments connect the pelvis and femur to reinforce the hip capsule (Figure 9). These ligaments are tight with the hip in extension and are most slack in the combined positions of flexion, abduction, and external rotation. The iliofemoral ligament (ligament of Bigelow) is the strongest of the three. It extends from 
the anterior inferior iliac spine (in two separate bands) to the anterior intertrochanteric line in an inverted-Y configuration. The primary role of the iliofemoral ligament is to resist hyperextension of the hip. The pubofemoral ligament attaches proximally to the superior pubic ramus and distally to the inferior femoral neck in order to provide resistance to hip hyperabduction. The ischiofemoral ligament, the thinnest of the three, extends from the ischial rim of the acetabulum, across the posteroinferior aspect of the hip joint, to insert on the femoral neck. Its primary function is to stabilize the joint in extension [17].

\section{Neuroanatomy}

The hip joint receives multiple innervations primarily involving the hip capsule. The posterior articular nerve, a branch of the nerve to the quadratus femoris provides the most extensive nerve supply to the hip joint, including the posterior and inferior regions of the capsule and the ischiofemoral ligament [15]. Superiorly, the hip capsule is innervated by the superior gluteal nerve. Anterior innervation of the capsule is provided, primarily, by direct branches of the femoral nerve. However, the anteromedial and anteroinferior regions are supplied by the medial articular nerve, which arises from the anterior division of the obturator nerve [15].
The ligamentum teres is innervated by the posterior branch of the obturator nerve [16]. Sensory nerve end organs and ramified free nerve endings are found in the acetabular labrum, suggesting that the labrum may provide nociceptive and proprioceptive feedback to and from the hip joint [18].

\section{Vascular Anatomy}

The hip joint receives its blood supply from several sources. The acetabulum is supplied by three main arteries: the obturator, the superior gluteal, and inferior gluteal (Figure 10). The superior gluteal artery supplies both the superior and posterior portions of the acetabulum, and the inferior gluteal artery supplies the inferior and posterior portions. The acetabular branch of the obturator artery provides the primary blood supply to the medial aspect of the acetabulum [15]. A smaller, terminal branch of the posterior division of the obturator artery, known as the foveal artery, traverses the ligamentum teres to supply a small area of the femoral head around the fovea centralis [17]. The recess between the capsule and labrum is lined with highly vascularized, loose connective tissue. A group of three to four small blood vessels is found in a circumferential pattern within the substance of the labrum and along the labrumbone junction [10].

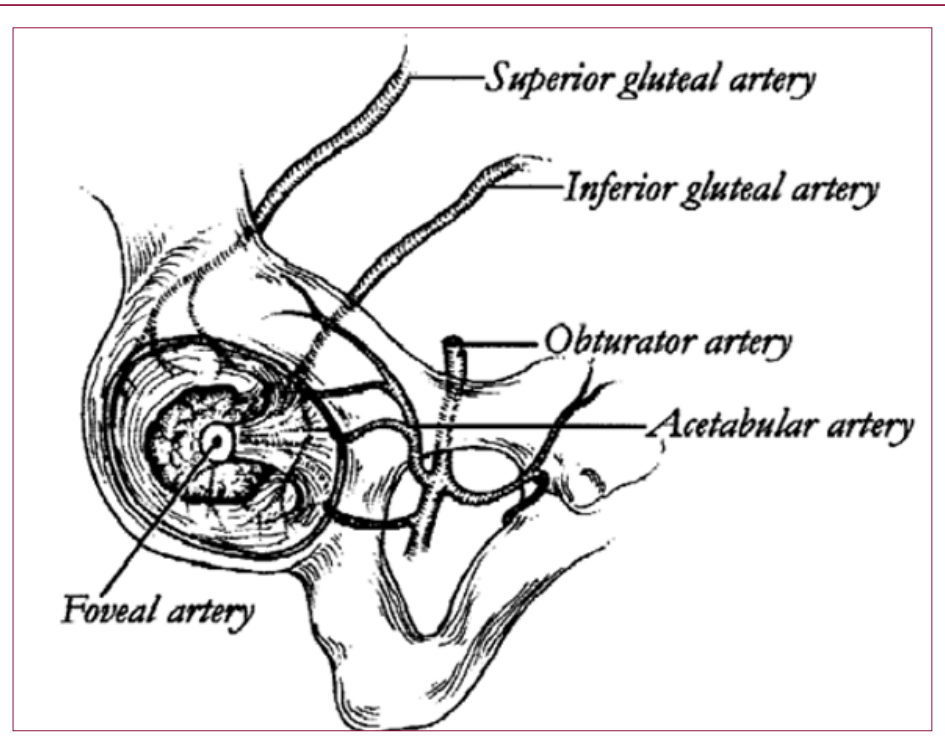

Figure 10: The blood supply to the acetabulum is provided by branches of the obturator, superior gluteal, and inferior gluteal arteries (Hansen, 1996).

The arterial supply to the proximal end of the femur has been studied extensively [19]. The description by Crock [19] seems the most appropriate because it is based on three-plane analysis and provides a standardization of anatomic nomenclature. Crock described the arteries of the proximal end of the femur in three groups: (a) an extracapsular arterial ring located at the base of the femoral neck; (b) ascending cervical branches of the extracapsular arterial ring on the surface of the femoral neck; and (c) the arteries of the round ligament [20].

The extracapsular arterial ring is formed posteriorly by a large branch of the medial femoral circumflex artery and anteriorly by branches of the lateral femoral circumflex artery (Figure 11). The superior and inferior gluteal arteries also have minor contributions to this ring [20]. The ascending cervical branches arise from the extracapsular arterial ring. Anteriorly, they penetrate the capsule of the hip joint at the intertrochanteric line and posteriorly, they pass beneath the orbicular fibers of the capsule. The ascending cervical branches pass upward under the synovial reflections and fibrous prolongations of the femoral head from its neck. These arteries are known as retinacular arteries, described initially by Weitbrecht [21].

Any fracture of the femoral neck may lead to an injury in the retinacular arteries due to its proximity. These ascending cervical arteries give a lot of small branches to the metaphysis of the femoral neck. Additional blood supply to the metaphysis arises from the extracapsular arterial ring and may include anastomoses with 
intramedullary branches of the superior nutrient artery system, branches of the ascending cervical arteries, and the subsynovial intra-articular ring. In the adult, there is communication through the epiphyseal scar between the metaphyseal and epiphyseal vessels when the femoral neck is intact [21].

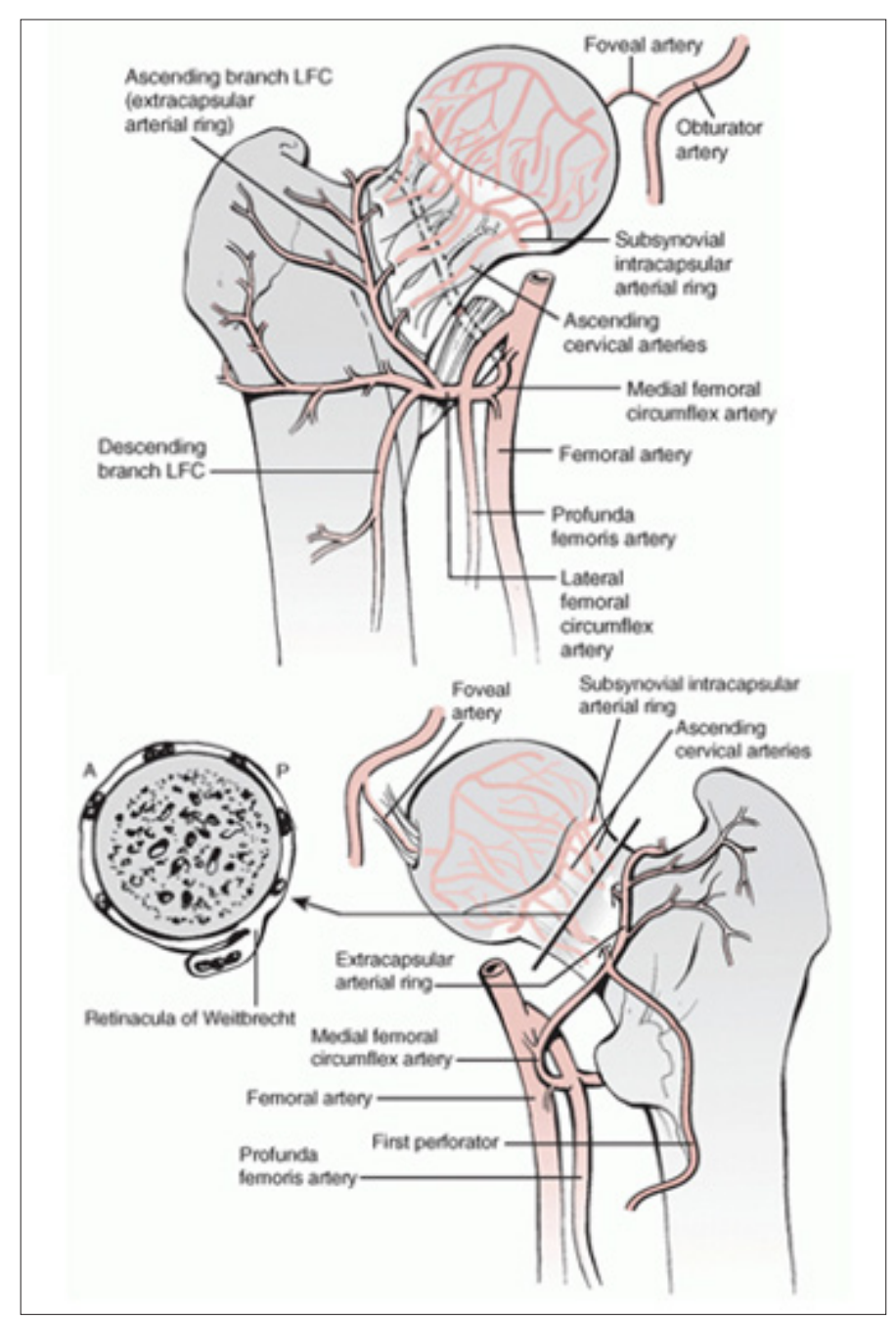

Figure 11: Vascular anatomy of femoral head \&neck. (Top) Anterior aspect. (Bottom) Posterior aspect. LFC, Lateral femoral circumflex artery (Leighton, 2006).

This excellent vascular supply to the metaphysis explains the absence of avascular changes in the femoral neck as opposed to the head [20]. The ascending cervical arteries can be divided into four groups (anterior, medial, posterior, and lateral) based on their relationship to the femoral neck. Of these four, the lateral group provides most of the blood supply to the femoral head and neck. At the margin of the articular cartilage on the surface of the neck of the femur, these vessels form a second ring, which Chung [22] has termed the subsynovial intra-articular arterial ring. At the subsynovial intra-articular ring, epiphyseal arterial branches arise that enter the femoral head. Disruption of this arterial ring has significance in high intracapsular fractures. Indeed, Claffey [23] demonstrated that in all femoral neck fractures that communicated with the point of entry of the lateral epiphyseal vessels, aseptic necrosis occurred [20].

Once the arteries from the subsynovial intra-articular ring penetrate the femoral head, they are termed the epiphyseal arteries. Two distinct groups of vessels within the femoral head were described by Trueta and Harrison (1953) as the lateral epiphyseal and inferior metaphyseal arteries. However, Crock [19] reported that these two groups of arteries actually arise from the same arterial ring and, hence, are both epiphyseal arteries [20].

The artery of the ligamentum teres is a branch of the obturator or the medial femoral circumflex artery [19]. The functional presence of this artery has been variably reported in the literature. Howe et al. [24] found that although the vessels of the ligamentum teres did supply vascularity to the femoral head, they were often inadequate to assume the major nourishment of the femoral head after a displaced femoral neck fracture. Claffey [23] also reported that simple patency of the vessels of the ligamentum teres did not make them capable of keeping the femoral head alive if all other sources of blood supply were interrupted [20].

\section{Muscular Anatomy}

The geometry of the hip allows wide range of motion in all planes, necessitating a large number of controlling muscles arising 
from a wide surface area to provide good stability (Table 1). The twenty-two muscles acting on the hip joint contribute to stability and provide the forces required for movement of the hip. The muscular anatomy of the hip region can be explained in many ways. Three groups could be defined into: 1-inner hip muscles, 2- outer hip muscles 3- muscles belonging to the adductor group [6]. Also, they can be classified as superficial and deep groups [4]. On the other hand, they can be divided into their main actions cross the hip joint [5].

Table 1: Muscles active on the hip joint: their origin, insertion, and innervation (Robbins, 1998).

\begin{tabular}{|c|c|c|c|c|}
\hline Action & Muscle & Origin & Insertion & Innervation \\
\hline \multirow{4}{*}{ 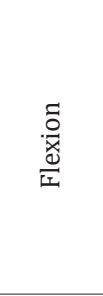 } & $\begin{array}{l}\text { Iliopsoas (iliacus, psoas major, } \\
\text { psoas minor) }\end{array}$ & $\begin{array}{l}\text { T12-L5 transverse processes, iliac } \\
\text { crest, and sacrum }\end{array}$ & Lesser trochanter & Femoral nerve \\
\hline & Rectus femoris & $\begin{array}{l}\text { AIIS and anterosuperior } \\
\text { acetabulum }\end{array}$ & Superior patella & Femoral nerve (L2-L4) \\
\hline & Tensor fascia latae & ASIS and iliac crest & Iliotibial tract & $\begin{array}{l}\text { Superior gluteal nerve (L4, } \\
\text { L5) }\end{array}$ \\
\hline & Sartorius & ASIS & Anteromedial tibial plateau & Femoral nerve (L2, L3) \\
\hline \multirow{4}{*}{ 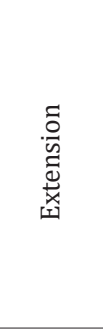 } & Gluteus maximus & $\begin{array}{l}\text { Outer cortex of ilium, posterior } \\
\text { sacrum and coccyx }\end{array}$ & $\begin{array}{l}\text { Posterior iliotibial tract and } \\
\text { gluteal tuberosity }\end{array}$ & $\begin{array}{l}\text { Inferior gluteal nerve (L5, } \\
\qquad \mathrm{S} 1, \mathrm{~S} 2)\end{array}$ \\
\hline & Biceps femoris & Ischial tuberosity & $\begin{array}{c}\text { Fibular head and } \\
\text { posterolateral tibial plateau }\end{array}$ & $\begin{array}{l}\text { Tibial branch of sciatic nerve } \\
\text { (L5, S1, S2) }\end{array}$ \\
\hline & Semimembranosus & Ischial tuberosity & Posteromedial tibial plateau & $\begin{array}{l}\text { Tibial branch of sciatic nerve } \\
\text { (L5, S1, S2) }\end{array}$ \\
\hline & Semitendinosus & Ischial tuberosity & Anteromedial tibial plateau & $\begin{array}{l}\text { Tibial branch of sciatic nerve } \\
\text { (L5, S1, S2) }\end{array}$ \\
\hline \multirow{3}{*}{ 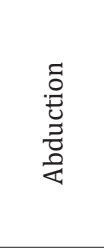 } & Gluteus medius & Anterior gluteal line & $\begin{array}{l}\text { Lateral surface of greater } \\
\text { trochanter }\end{array}$ & $\begin{array}{l}\text { Superior gluteal nerve (L4, } \\
\text { L5, S1) }\end{array}$ \\
\hline & Gluteus minimus & Outer cortex of ilium & $\begin{array}{l}\text { Anterior surface of grater } \\
\text { trochanter }\end{array}$ & $\begin{array}{l}\text { Superior gluteal nerve (L5, } \\
\text { S1) }\end{array}$ \\
\hline & Tensor fascia latae & ASIS and iliac crest & Iliotibial tract & $\begin{array}{c}\text { Superior gluteal nerve (L4, } \\
\text { L5) }\end{array}$ \\
\hline \multirow{3}{*}{ 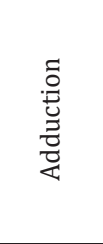 } & Adductor magnus & $\begin{array}{l}\text { Inferior pubic ramus, ischial } \\
\text { tuberosity }\end{array}$ & $\begin{array}{c}\text { Gluteal tuberosity and } \\
\text { adductor tubercle of medial } \\
\text { femur }\end{array}$ & $\begin{array}{l}\text { Obturator nerve (L2, L3) and } \\
\text { sciatic nerve (L2-L4) }\end{array}$ \\
\hline & Adductor longus & Body of pubis & Middle third of linea aspera & Obturator nerve (L2-L4) \\
\hline & Adductor brevis & Inferior ramus and body of pubis & $\begin{array}{l}\text { Proximal linea aspera and } \\
\text { pectineal line }\end{array}$ & Obturator nerve (L2-L4) \\
\hline \multirow{3}{*}{ 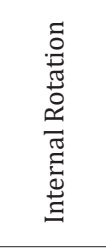 } & Gluteus medius & Anterior gluteal line & $\begin{array}{l}\text { Lateral surface of greater } \\
\text { trochanter }\end{array}$ & $\begin{array}{l}\text { Superior gluteal nerve (L4, } \\
\text { L5, S1) }\end{array}$ \\
\hline & Gluteus minimus & Outer cortex of ilium & $\begin{array}{l}\text { Anterior surface of grater } \\
\text { trochanter }\end{array}$ & $\begin{array}{l}\text { Superior gluteal nerve (L5, } \\
\text { S1) }\end{array}$ \\
\hline & Tensor fascia latae & ASIS and iliac crest & Iliotibial tract & $\begin{array}{l}\text { Superior gluteal nerve (L4, } \\
\text { L5) }\end{array}$ \\
\hline \multirow{6}{*}{ 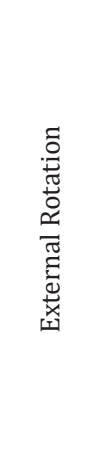 } & Obturator internus & $\begin{array}{l}\text { Inner surface of obturator } \\
\text { membrane }\end{array}$ & Medial greater trochanter & $\begin{array}{l}\text { Nerve to obturator internus } \\
\text { (L5, S1) }\end{array}$ \\
\hline & Obturator externus & $\begin{array}{l}\text { Outer surface of obturator } \\
\text { membrane, pubic ramus, and } \\
\text { ischium }\end{array}$ & Trochanteric fossa & Obturator nerve (L3, L4) \\
\hline & Superior gemellus & Ischial spine & Posterior greater trochanter & $\begin{array}{l}\text { Nerve to obturator internus } \\
\text { (L5, S1) }\end{array}$ \\
\hline & Inferior gemellus & Ischial tuberosity & Posterior greater trochanter & Nerve to quadratus femoris \\
\hline & Piriformis & $\begin{array}{l}\text { Anterior surface of the sacrum and } \\
\text { sacrotuberous ligament }\end{array}$ & $\begin{array}{l}\text { Posterosuperior grater } \\
\text { trochanter }\end{array}$ & Ventral rami of S1 and S2 \\
\hline & Quadratus femoris & Lateral border of ischial tuberosity & Quadrate tubercle & Nerve to quadratus femoris \\
\hline
\end{tabular}

The muscles of the hip region is invested in a fibrous layer called the fascia lata., which is a continuous fibrous sheath surrounding the thigh. It is attached to the inguinal ligament, posterior aspect of the sacrum, lip of the iliac crest, the ischial tuberosity, the body of the pubis and the pubic tubercle proximally. The inelastic nature of this fascia acts to limit bulging of the thigh muscles that's leads to improve the efficiency of their contractions [7].

The major flexor of the hip joint is iliopsoas group; psoas major, psoas minor and iliacus. The origin of the psoas major is from T12 to $\mathrm{L} 5$ vertebral bodies and it inserts into the lesser trochanter. It 
is joined at the level of the inguinal ligament to form the iliopsoas $[6,7]$. Iliopsoas is the acting hoarse in hip flexion, but it is also aided by sartorius, tensor fascia, rectus femoris and latae (TFL) [6]. Sartorius, innervated by the femoral nerve, runs from the Anterior Superior Iliac Spine (ASIS) to insert medial to the tibial tuberosity. It plays a role external rotation and hip abduction. Rectus femoris originates from the AIIS to be inserted into the tibial tuberosity through the patellar ligament [5]. Gluteus maximus is considered the main hip extensor. Originating from the dorsal sacral surface, posterior part of the ilium and thoracolumbar fascia to be inserted into the gluteal tuberosity and the iliotibial tract $[6,7]$. It receives innervation from the inferior gluteal nerve. It plays a role in external rotation, abduction and adduction [5].

The main hip abductors are gluteus medius and minimus. The proximal insertion of gluteus medius into the iliac crest is almost continuous with fascia lata. It appears as an inverted triangle from its wide proximal base to its narrow disral insertion into the lateral aspect of the greater trochanter. Gluteus minimus lies beneath gluteus medius. It arises from the gluteal surface of the ilium and inserts into the anterolateral aspect of the greater trochanter. Both muscles receive innervations through the superior gluteal nerve [5]. Tensor Fascia Lata takes its origin from the ASIS to be inserted distally into the iliotibial tract. It shares in flexion and external rotation. Piriformis muscles arises from the inner surface of the sacrum and inserts into the tip of the greater trochanter. It plays a role in hip extension and external rotation [5].

The external rotators (superior gemellus, obturator internus, inferior gemellus, and quadratus femoris) run horizontally below the piriformis. All play a role in hip adduction and external rotation and all receive branches from L5-S1 in the sacral plexus $[6,7]$. Hip adductors include the obturator externus arising from the outer surface of the obturator membrane and inserting into the trochanteric fossa. It also contributes to external rotation and has its innervation from the obturator nerve. The remaining muscles in this group variably have their proximal origin on the pubic bone and insert distally on the femur below the level of the lesser trochanter or in the case of gracilis into the pes anserinus medial to the tibial tubercle [5].

Pectineus attaches at the pectin pubis and inserts into the femur along the pectineal line and linea aspera. It also contributes to external rotation and some flexion. Adductor longus attaches medial to pectineus on the superior pubic ramus and inserts distally to the pectineus along the middle third of the linea aspera - it also contributes to hip flexion up to $70^{\circ}$ [6]. Adductor brevis arises from the inferior pubic ramus and inserts proximal to adductor longus into the proximal one third of the linea aspera. Adductor magnus arises from the inferior pubic ramus, ischial ramus and ischial tuberosity. It inserts distally into the medial lip of the linea aspera but also has a more tendinous insertion into the medial condyle of the femur. It contributes also to extension and external rotation. Adductor minimus runs from the inferior pubic ramus into the medial lip of the linea aspera also contributing to external rotation. Gracilis is the only adductor that inserts distal to the knee joint. It arises inferior to the pubic ramus below the pubis symphysis. All the adductors receive an innervation from the obturator nerve.
Pectineus also has a supply from the femoral while the deep aspect of adductor magnus also has a supply from the sciatic nerve [5].

As previously stated, the muscles of the hip joint can contribute to movement in several different planes depending on the position of the hip, which is caused by a change in the relationship between a muscle's line of action and the hip's axis of rotation. This is referred to as the "inversion of muscular action" and most commonly manifests as a muscle's secondary function. For example, the gluteus medius and minimus act as abductors when the hip is extended and as internal rotators when the hip is flexed. The adductor longus acts as a flexor at $50^{\circ}$ of hip flexion, but as an extensor at $70^{\circ}$ [5].

In addition to providing stability and motion for the hip, muscles act to prevent undue bending stresses on the femur. When the femoral shaft undergoes a vertical load, the lateral and medial sides of the bone experience tensile and compressive stresses respectively. To resist these potentially harmful stresses, as might occur in the case of an elderly person whose bones have become osteoporotic and susceptible to tensile stress fractures, the TFL acts as a lateral tensioning band [5].

Muscle weakness around the hip is usually compensated by the individual to perform the desired task of walking. An example is the Trendelenburg gait, noted by the pelvis sagging to the contralateral side secondary to weakness of the abductor muscle group on the weight-bearing side. This is countered by the individual shifting their center of gravity towards the affected joint by leaning over. This tilting reduces the force required by the abductors [5].

\section{Biomechanics}

Joint motion is described as rotations and translations occurring in the $\mathrm{x}, \mathrm{y}$, and $\mathrm{z}$ planes, requiring 6 parameters or degrees of motion. It is important to note that not all joints exhibit 6 degrees of freedom (abduction, adduction, flexion, extension, internal rotation, and external rotation) due to anatomic constraints to motion [25]. The hip is a joint that does exhibit 6 degrees of freedom and is termed a ball and socket joint. The stability of the hip joint depends mainly on the ball and socket design. The bone of the hip is also designed to withstand All stress that is placed upon it during daily activities [25].

The bone structure of the proximal femur is characterized by typical compression and tension trajectories formed according to Wolff's law of transformation by bending stresses acting on the femur at the hip. The alignment of these trajectories depends on the loading and the shape of the proximal end of the femur. The bone structure at the acetabulum is also influenced by shape and loading. The smaller the loaded area and the greater the overall load, the more likely it is that a sclerotic section will form [11].

The femoral neck has two angular relationships with the femoral shaft that are important to hip joint function: the angle of inclination of the neck to the shaft in frontal plane (the neck-to-shaft angle) and the angle of inclination in the transverse plane (the angle of anteversion). Freedom of motion of the hip joint is facilitated by the neck-to-shaft angle, which offsets the femoral shaft from the pelvis laterally. Deviation of the femoral shaft in either way alters 
the force relationships about the hip joint and has nontrivial effect on the lever arms to muscle force and line of gravity [26].

This structure allows anterior/posterior and medial/lateral translation in addition to subluxation; however, it does not generally limit the range of motion of the hip during normal daily activities. The allowable range of motion is shown in Table 2 when compared to a selection of usual daily activities [27]. The range of

Table 2: Range of motion (degrees) in hip compared to daily activities.

\begin{tabular}{|c|c|c|c|}
\hline & Allowable [1] & Walking [2,3] & Tie Shoe [4] \\
\hline Flexion/extension & $140 / 30$ & $30 / 15$ & 129 \\
\hline Internal/external rotation & $90 / 90$ & $4 / 9$ & 13 ext. \\
\hline Abduction/adduction & $90 / 30$ & $7 / 5$ & $18 a b d$. \\
\hline
\end{tabular}

Basic analytical approaches to the balance of forces and moments about the hip joint can be useful in estimating the effects of alterations in joint anatomy or different treatment modalities on the hip joint reaction force [28]. Two-dimensional analysis can help in understanding the static loading of the hip joint. In double leg stance, the center of gravity lies between both hips and its force is exerted equally on both sides. Under this load, the weight of the body minus the weight of both legs is supported equally on the femoral heads, and the resultant vectors are vertical [5].

In a single leg stance, the center of gravity moves away from the supporting leg since the non-supporting leg is now considered motion of the hip joint is greater than what is required for usual daily activities, such as walking. Muscle forces are the main corner stone in the stability of the hip joint during the walking cycle [27]. The reactive force of the hip can reach three to six times body weight, primarily due to the contraction of muscles that cross the hip joint. These muscles, primarily the abductor group (the gluteus medius and minimus) confer stability to the hip and are important in stabilizing the pelvis during gait [25]. a part of the body mass acting upon the weight-bearing hip (Figure 12). This downward force produces a rotatory motion around the femoral head - the moment is created by the body weight, $\mathrm{K}$, and its moment arm, a (distance from femur to the center of gravity). The muscles that resist this movement are offset by the combined abductor muscles, M. This group of muscles includes the upper fibres of the gluteus maximus, the tensor fascia lata, the gluteus medius and minimus, and the piriformis and obturator internus. The abductor muscles create a moment around the femoral head; however, this moment arm is shorter than the effective lever arm of body weight. Therefore, the combined force of the abductors must be a multiple of body weight [5].

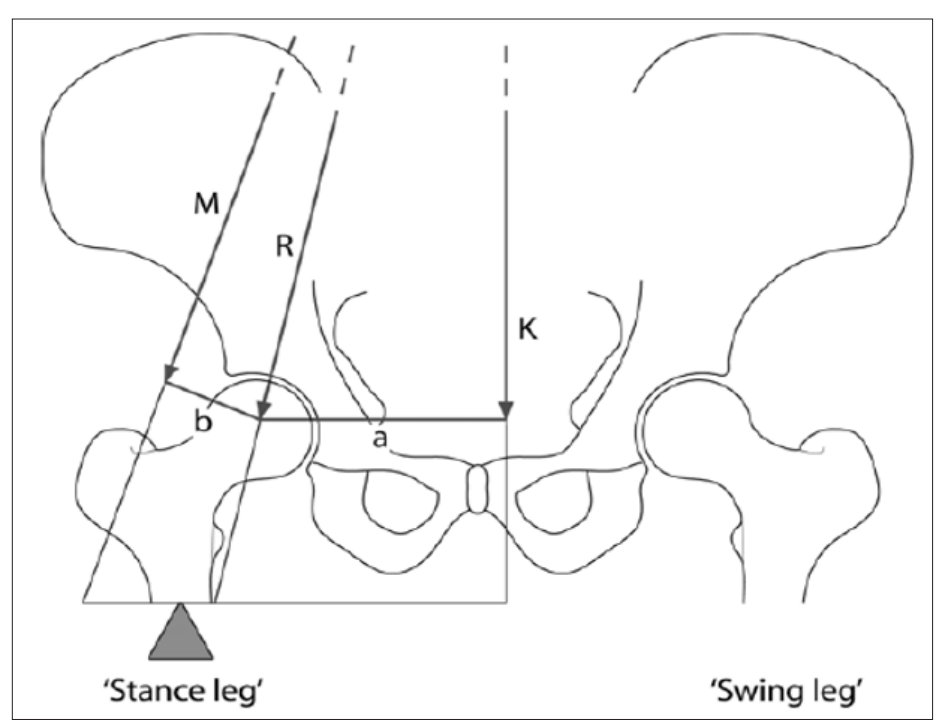

Figure 12: Free-body diagram for the calculation of the hip joint force while walking, where $\mathrm{K}$ is the body weight (minus the weight bearing leg), $\mathrm{M}$ is the abductor muscle force, and $\mathrm{R}$ is the joint reaction force (Damien et al., 2010).

The magnitude of the forces depends critically on the lever arm ratio, which is that ratio between the body weight moment arm and the abductor muscle moment arm (a:b) [29]. Typical levels for single leg stance are three times bodyweight, corresponding to a level ratio of 2.5. Thus, anything that increases the lever arm ratio also increases the abductor muscle force required for gait and consequently the force on the head of the femur as well (Figure 13). People who have short femoral necks or a wide pelvis have higher hip forces, other things being equal. This tendency means that women have larger hip forces than men because their pelves must accommodate a birth canal [30].

Initial calculations with a two-dimensional model were first made by Pauwels [31]. In a normal hip, the force resultant acting on the hip is approximately four times the body weight. If the femoral neck angle is greater than normal, and the lever arm of the abductors correspondingly shorter, the force resultant increases. The reverse situation applies with coxa vara, in which the femoral neck angle is smaller, thus lengthening the lever arm of the abductors and thus decreasing the resultant force (Figure 14) [11]. 


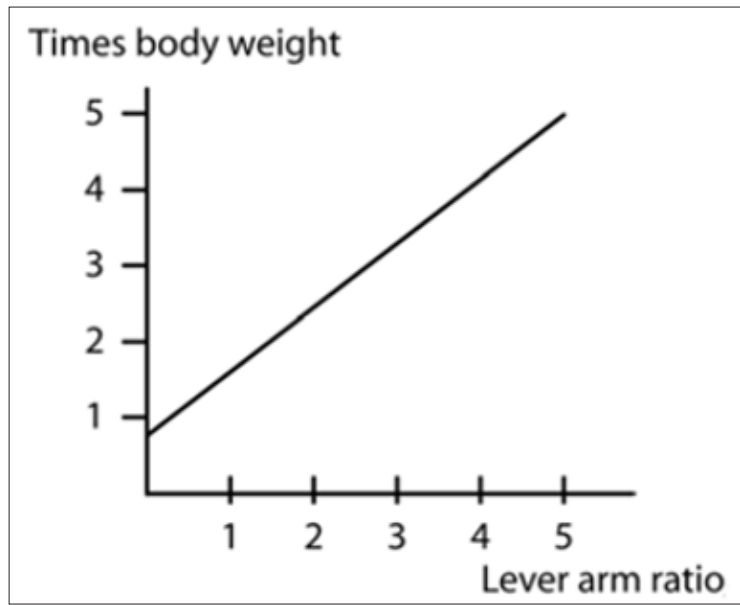

Figure 13: Effect of lever arm ratio on the hip joint reaction force, adapted from Greenwald (1991).

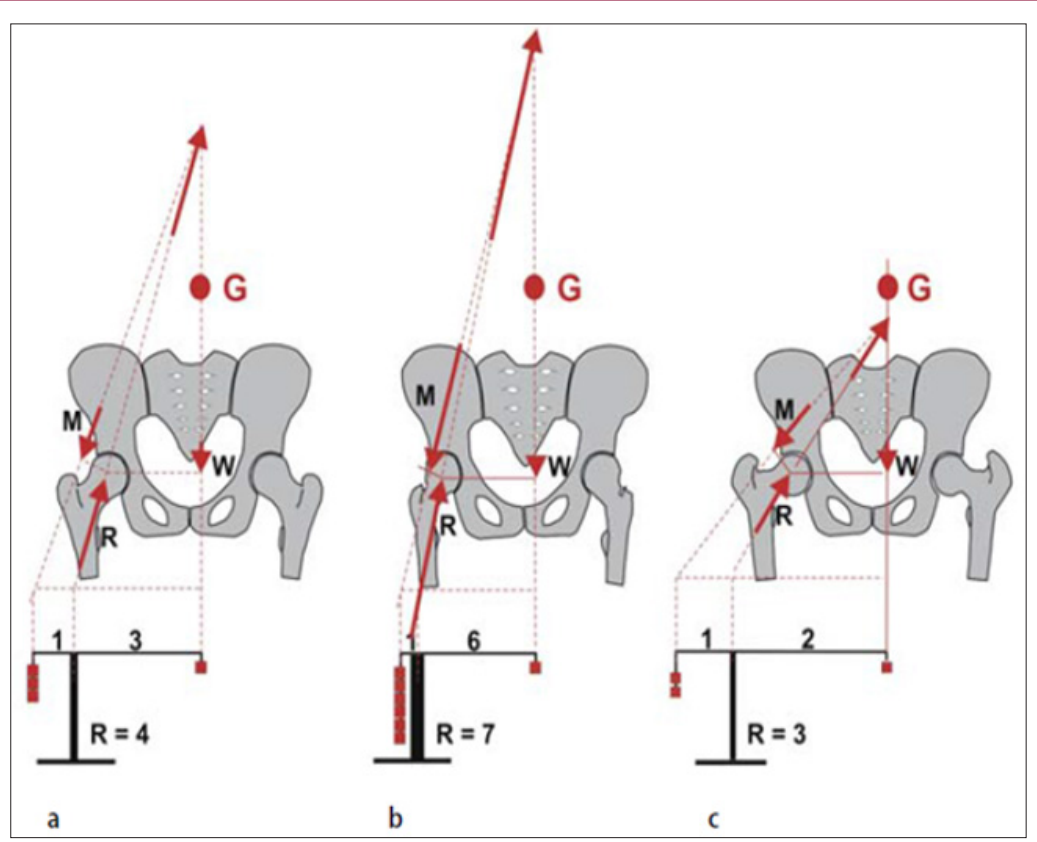

Figure 14: Schematic view of the forces in the hip according to Pauwels a in the normal hip, $b$ valgus hip and $c$ varus hip. The diagram shows the effect produced by a change in the lever arms on the acting forces (G Center of gravity, W Body weight, $\mathrm{R}$ Force resultant in the hip, M Force of the abductors) (Hefti, 2007).

However, Pauwels' calculations are based on a two-dimensional model and can only provide rough approximations. By no means should one conclude that an increased femoral neck-shaft angle necessarily results in overloading of the hip. Firstly, the valgus position of the proximal end of the femur does not exist in reality, but only produces a coxa valga in projection if the anteversion angle is elevated. Secondly, the loading of the hip cannot be determined from just one single parameter since a wide variety of factors are involved. The varus osteotomy that often used to be implemented on the basis of theoretical considerations resulted in the recurrence of a valgus position during subsequent growth, as this was required by the anatomical circumstances in a given hip [11]. Recent investigations with cadaver bones have shown that the trochanteric apophysis is primarily loaded in compression, and that the force resultant is approx. 1.7 times the body weight. This stimulates craniolateral growth and therefore also influences the development of the neck-shaft angle [32].

Principles of simple static mechanics analyze the loading applied within the body during dynamic situations, such as running or walking. Figure 15 shows a very simple 2-dimensional (2D) schematic of the leg at the heel-strike phase of gait. Contact with the ground produces a ground reaction force the same as the proportion of the person's mass transferred to the ground multiplied by the acceleration of this mass (gravitational acceleration+ linear acceleration).At the heel strike the knee is fully extended and can be analyzed in a seesaw manner as shown in Figure 16 with the hip joint acting as the pivot. The ground reaction force acting at the foot (Fgr) produces a counterclockwise (positive) moment about the hip center equal to Fgr $\times$ Gr. The moment arm Gr is equal to the length of the leg (L) multiplied by the sine of the flexion angle $\left(30^{\circ}\right)$; $\mathrm{Gr}$ is, therefore, equal to $0.5 \mathrm{~L}$. Thus, the ground reaction force (Fgr) produces a flexion moment of body weight $(\mathrm{BW}) \times 0.5 \mathrm{~L}$ [27]. 
The flexion moment is balanced by the extensor muscles including the gluteus maximus and the hamstrings which act to stabilize the hip at heel-strike producing a counterclockwise negative moment. In this example, for simplicity, the hamstrings muscle alone has been considered. The moment produced by the hamstrings muscle is equal to the magnitude of the hamstrings muscle force $(\mathrm{Fh})$ multiplied by the distance from the line of action of the muscle to the hip center. Thus, the moment arm will vary from person to person; however, its value will be approximated in this example to be equal to $0.15 \mathrm{~L}$. Therefore, the moment produced by the hamstrings muscle group would be equal to $\mathrm{Fh} \times 0.15 \mathrm{~L}$. For the hip to be stable the ground reaction moment $(\mathrm{BW} \times 0.5 \mathrm{~L})$ must be approximately equal to the moment produced by the extensor muscles, in this case only the hamstrings. Therefore, the hamstrings muscle force $\mathrm{Fh}$ at gross approximation would be equal to 3.3 times
BW [27].

The vertical reaction force at the hip can be calculated by summing the forces acting in the vertical direction from Figure 15. This includes the ground reaction force Fgr and the vertical component of the hamstrings muscle force vector Fhos $(30+\theta 0)$, where $\theta$ is the angle between the hamstrings muscle force vector and the line of action of the femur. In this case, $\theta$ is assumed to be equal to $17^{\circ}$. Therefore, for this simple example, the vertical reaction force at the hip is equal to $\mathrm{BW}+3.3 \mathrm{BW} \times 0.68$ for a total of $3.25 \mathrm{BW}$. This $2 \mathrm{D}$ calculation is very crude; however, it demonstrates the general methods which can be utilized to analyses forces and moments in the body. It also demonstrates the inefficiency of our muscle forces due to the nature of our relatively long slender limbs and the resulting short muscular moment arms [27].

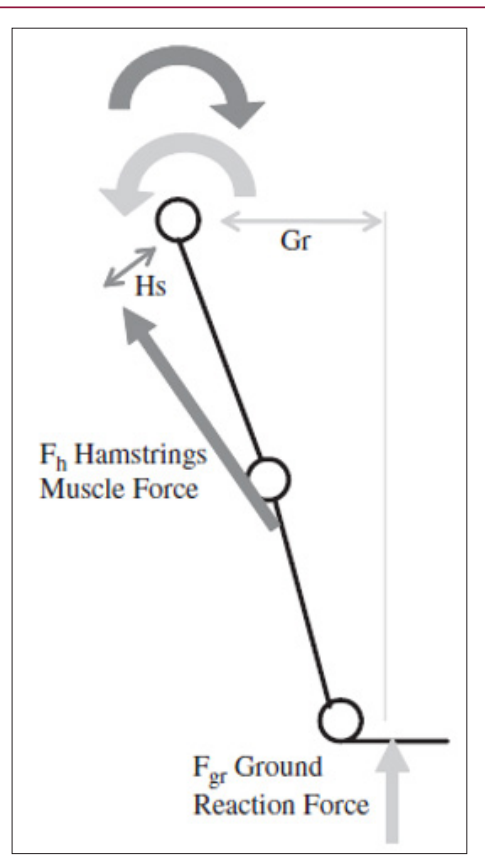

Figure 15: Simplified 2D Kinetics of heel-strike, where Gr is ground moment arm, Hs hamstrings muscle moment arm, Fh is hamstrings muscle force and Fgr is ground reaction force (Stewart and Hall, 2006).

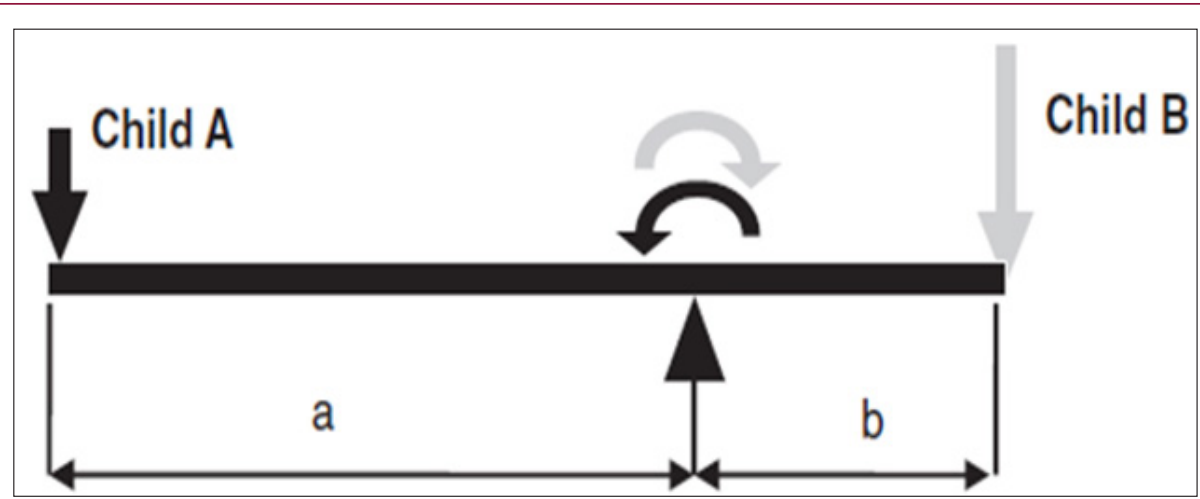

Figure 16: Schematic of a seesaw (Stewart and Hall, 2006).

The vertical hip joint reaction force characteristics during walking are (Figure 17) two peaks of load at heel-strike and at toeoff which generally range from 3-4 times our body weight. Between these two loading peaks the body's mass moves smoothly and does not show a large vertical migration. So, the hip reaction force between heel-strike and toe-off is tiny and in the region of body weight. At toe-off the hip is extended 15 degrees. The quadriceps muscle acts as a stabilizer to the knee whilst the gastrocnemius muscle produces plantar flexion at the ankle. These muscles act to accelerate the body forward creating a second peak in the reaction force curve [27, 33-38]. 


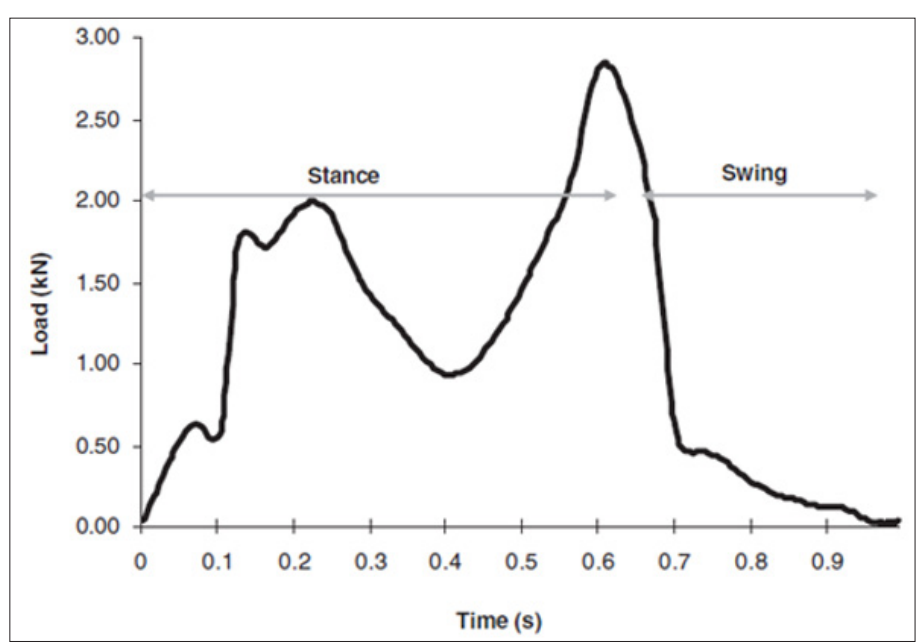

Figure 17: Vertical reaction force at the hip joint during walking (Stewart and Hall, 2006).

\section{References}

1. Strayer LM (1971) The embryology of the human hip. Clin Orthop Rel Res 74: 221-240.

2. Portinaro NM, Murray DW, Benson MKD (2001) Microanatomy of the acetabular cavity and its relation to growth. J Bone Joint Surg Br 83(3): 377-383.

3. Ogden JA (1983) Development and growth of the hip. In: Management of Hip Disorders in Children, edited by Katz JE, Siffert RS (Eds.); Lippincott, Philadelphia, p. 1-32.

4. Byrd J (2004) Gross anatomy. In: Operative Hip Arthroscopy, ( $2^{\text {nd }}$ edn); edited by Byrd J, Springer Science, New York, USA, pp. 100-109.

5. Damien P Byrne, Kevin J Mulhall, Joseph F Baker (2010) Anatomy \& Biomechanics of the Hip. Open Sports Med J 4(1): 51-57.

6. Schuenke M, Schutle E, Schumacher U (2006) Lower Limb: Bones, ligaments and joints. In: THIEME Atlas of Anatomy: General Anatomy and Musculoskeletal System, ( $1^{\text {st }}$ edn); edited by Ross L, Lamperti E, Georg Thieme Verlag, Stuttgart; New York, USA, pp. 360-418.

7. Moore KL (1992) The Lower Limb. In: Clinically Oriented Anatomy, (3 ${ }^{\text {rd }}$ edn); edited by Moore KL, Williams and Wilkins, USA, pp. 373-495.

8. Kim YH (1987) Acetabular dysplasia and osteoarthritis developed by an eversion of the acetabular labrum. Clin Orthop Relat Res 215: 289-295.

9. Ferguson SJ, Bryant JT, Ganz R, Ito K (2003) An in vitro investigation of the acetabular labral seal in hip joint mechanics. J Biomech 36(2): 171178.

10. Seldes RM, Tan V, Hunt J, Katz M, Winiarsky R (2001) Anatomy, histologic features and vascularity of the adult acetabular labrum. Clin Orthop Relat Res 382: 232-240.

11. Hefti F (2007) Pelvis, hips and thighs: Biomechanics of the hip. In Pediatric Orthopedics in Practice. Springer-Verlag Berlin Heidelberg, New York, USA, pp. 169-176.

12. Ward FO (1838) Human Anatomy. Renshaw.

13. Harty M (1957) The calcar femorale and the femoral neck. J Bone Joint Surg Am 39(3): 625-630.

14. Griffin JB (1982) The calcar femorale redefined. Clin Orthop 164: 211214.

15. Robbins CE (1998) Anatomy and biomechanics, In: The Hip Handbook edited by Fagerson TL (Eds.); Boston, MA: Butterworth-Heinemann, p. $1-37$.

16. Harty M (1984) The anatomy of the hip joint. In: Surgery of the Hip Joint, $\left(2^{\text {nd }}\right.$ edn); edited by Tronzo R, Springer-Verlag, New York, p. 49-74.
17. Sim FH, Rock MG, Scott SG (1995) Pelvis and hip injuries in athletes: Anatomy and function. In: The Lower Extremity \& Spine in Sports Med ( $\left.2^{\text {nd }} e d n\right)$; edited by Nicholas JA and Hershman EB, Saint Louis, MO: Mosby, pp. 1025-1065.

18. Kim YT, Azuma H (1991) The nerve endings of the acetabular labrum. Clin Orthop 320: 176-181.

19. Crock HV (1980) An atlas of the arterial supply of the head and neck of the femur in man. Clin Orthop 152: 17-27.

20. Leighton RK (2006) Fractures of the neck of the femur. In: Rockwood \& Green's Fractures in Adults, ( $6^{\text {th }}$ edn); edited by Bucholz RW, Heckman JD, Court-Brown CM, Lippincott Williams \& Wilkins, pp. 1754-1756.

21. Weitbrecht J (1942) Syndesmologia sive Historia Ligamentorum Corporis Humani guain Seeundum. Observationes Anatomicas Concinnavit et Figuris and Objecta Reentia Adumbratis Illustravit. Petropoli Typogr Acad Sci pp. 139-141.

22. Chung SMK (1976) The arterial supply of the developing proximal end of the human femur. J Bone Joint Surg Am 58(7): 961-965.

23. Claffey TJ (1960) Avascular necrosis of the femoral head: An anatomical study. J Bone Joint Surg Br 42: 802-809.

24. Howe JWW, Lacey IT, Schwartz RP (1950) A study of the gross anatomy of the arteries supplying the proximal portion of the femur and the acetabulum. J Bone Joint Surg Am 32(4): 856-865.

25. Reddy S, Dischino M Soslowsky LJ (2009) Biomechanics - Part I. In: Bone Pathology, edited by Khurana JS (Eds.); Humana Press a part of Springer Science Business Media, p. 61-68.

26. Nordin M, Frankel VH (2001) Biomechanics of the Hip. In: Basic Biomechanics of the Musculoskeletal System, ( $3^{\text {rd }}$ edn $)$; edited by Nordin M and Frankel VH, Lippincot Williams \& Wilkins, pp. 203-221.

27. Stewart TD, Hall RM (2006) Basic biomechanics of human joints: Hips, knees and the spine. Curr Orthop 20(1): 23-31.

28. Johnston JD, Noble PC, Hurwitz DE, Andriacchi TP (1998) Biomechanics of the hip. In: The Adult Hip, edited by Callaghan J, Rosenberg AG, Rubas HE (Eds.); Lippincott Williams \& Wilkins, Philidalphia, p. 81-90.

29. Martin RB, Burr DB, Sharkey NA (1998) Skeletal tissue mechanics, Springer, USA, pp. 392.

30. Burr DB, Gerven DPV, Gustav BL (1977) Sexual dimorphism and mechanics of the human hip: A multivariate assessment. Am J Phys Anthropol 47(2): 273-278.

31. Pauwels F (1935) Der Schenkelhalsbruch ein mechanisches Problem. Z Orthop Ihre Grenzgeb 63: 1-135. 
32. Heimkes B, Posel P, Plitz W, Jansson V (1993) Forces acting on the juvenile hip joint in the one-leg-stance. J Pediatr Orthop 13(4): 431-436.

33. Andriacchi TP, Anderson GBJ, Fermier RW, Stern D, Galante JO (1980) A study of lower limb mechanics during stair climbing. J Bone Joint Surg 62(5): 749-757.

34. D'Lima DD, Urquhart AG, Buehler KO, Walker RH, Colwell CW (2000) The effect of the orientation of the acetabular and femoral components on the range of motion of the hip at different head neck ratios. J Bone Joint Surg 82(3): 315-321.

\section{ISSN: 2574-1241}

DOI: $10.26717 / B J S T R .2018 .12 .002267$

Ahmed Zaghloul. Biomed J Sci \& Tech Res

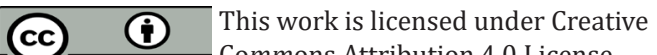
Commons Attribution 4.0 License

Submission Link: https://biomedres.us/submit-manuscript.php
35. Heller MO, Bergmann G, Deuretzbacher G, Durselen L, Pohl M, et al. (2001) Musculoskeletal loading conditions at the hip during walking and stair climbing. J Biomech 34(7): 883-893.

36. Houston CS, Zaleski WA (1967) The shape of vertebral bodies and femoral necks in relation to activity. Radiology 89(1): 59-66.

37. Johnson RC, Smidt GL (1969) Measurement of hip-joint motion during walking. J Bone Joint Surg 51(6): 1083-1094.

38. Kapandji IA (1987) The Hip. In: Physiology of the joints: Lower limb, ( $5^{\text {th }}$ edn); Churchill Livingstone, Edinburgh, p. 2-65.

$\begin{array}{ll}\text { BIOMEDICAL } & \text { Assets of Publishing with us } \\ \text { RESEARCHES } & \text { - Global archiving of articles } \\ & \text { - Immediate, unrestricted online access } \\ & \text { - Rigorous Peer Review Process } \\ \end{array}$

